\title{
Gastroprotective effect of leaf extracts of Basella alba var. alba against experimental gastric ulcers in rats
}

\author{
Vijender Kumar, ${ }^{* 1}$ Z. A. Bhat, ${ }^{1}$ Dinesh Kumar, ${ }^{1}$ N. A. Khan, ${ }^{1}$ I. \\ A. Chashoo, ${ }^{1}$ Irfat Ara $^{2}$
}

${ }^{1}$ Department of Pharmaceutical Sciences, University of Kashmir, India, ${ }^{2}$ Regional Research Institute of Unani Medicine, India.

\begin{abstract}
The aqueous and ethanol extracts of the leaves of Basella alba L. var. alba Wight, Basellaceae, were investigated for antiulcer activity on rats employing the pylorus ligation and ethanol induced ulcer models. The various gastric secretion parameters such as total acidity, free acidity, gastric acid volume, $\mathrm{pH}$ and histopathological parameters such as ulcer index and percent protection were comparatively examined between control, test and standard groups. The antiulcer activity of aqueous extract of $B$. alba (AEBA) and ethanol extract of $B$. alba (EEBA) were studied in rats treated with the doses of $1 \mathrm{~mL} / \mathrm{kg}$ of absolute ethanol, 200 and $400 \mathrm{mg}$ of test extracts and $20 \mathrm{mg} / \mathrm{kg}$ of famotidine for control, test and standard groups respectively in both the models. The animals pretreated with AEBA and EEBA showed a dose-dependent protection against gross damaging action of ethanol and pylorus ligation on gastric mucosa of animals. Histopathological evaluation also revealed that Group I treated with absolute ethanol showed severe gastric mucosal damage. The AEBA and EEBA showed 68.25 and $58.11 \%$ protection in gastric mucosal damage as compared to control group. Both the extracts of $B$. $a l b a$ var. alba were able to decrease the gastric acidity and increase the mucosal defense in the gastric mucosal area. This study indicate that $B$. alba var. alba possesses significant gastroprotective effect and the same is substantiated by the histopathological examination of the ulcerated stomachs of the animals.
\end{abstract}

Revista Brasileira de Farmacognosia Brazilian Journal of Pharmacognosy 22(3): 657-662, May/Jun. 2012

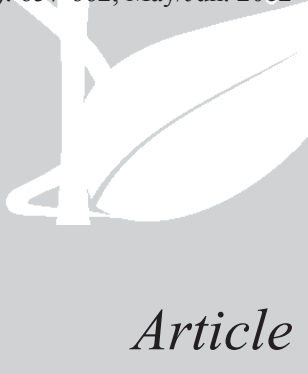

Article

Received 9 Sep 2011

Accepted 18 Nov 2011

Available online 8 Mar 2012

Keywords: anti-ulcer Basella alba famotidine gastric ulcer pylorus ligation

ISSN 0102-695X http://dx.doi.org/10.1590/S0102695X2012005000032

\section{Introduction}

Basella alba L. var. alba Wight, Basellaceae, is known as "Poi" (Hindi), "Potaki" (Sanskrit) and "Indian spinach" in English (Nandkarni, 19760). The stems and leaves of $B$. alba are thick, sweet, mucilaginous and used in constipation, as diuretic, in urticaria, as demulcent, antiulcer, and as cooling application for burn (Pareek et al., 2010). Peptic ulcer occurs in two main forms i.e. acute peptic ulcer and chronic peptic ulcer. Acute peptic ulcer penetrates the lamina muscularis mucosa but does not extend more deeply than the submucosa. It is mainly related to stress and present in the form of severe burns (Curlings ulcer) and brain damage (Cushing's ulcer). The chronic peptic ulcer which penetrates the full thickness of the muscularis propria and has its base in the serosal layer of the organ involved or out with the gut altogether. The common forms of peptic ulcer are duodenal ulcer (DU), gastric ulcer (GU), stress ulcer, non steroidal antiinflammatory drug (NSAID) induced ulcers and recurrent oral ulceration also known as aphthous ulceration (Vyawahare et al., 2009). The etiology of gastro duodenal ulcers is influenced by various aggressive and defensive factors such as acid-pepsin secretion, parietal cell, mucosal barrier, mucus secretion, blood flow, cellular regeneration and endogenous protective agents such as prostaglandins and epidermic growth factors. Some other factors, such as inadequate dietary habits, excessive ingestion of nonsteroidal anti-inflammatory agents, stress, hereditary predisposition and infection by Helicobacter pylori may be responsible for the development of peptic ulcer (Khandare et al., 2009). A number of synthetic antiulcer drugs such as H2-receptor antagonists, proton pump inhibitors and cytoprotectants are available for the treatment of ulceration. All these drugs have a number of side effects and limitations. We have studied the antiulcer potential of $B$. alba leaf extracts and compared it with famotidine as standard drug. B. alba is used as vegetable in Tripura and in traditional medicinal preparations especially for the treatment of constipation, as diuretic, in urticaria, as demulcent, antiulcer, as cooling application for burns and in toothache. This study revealed a significant anti-ulcer effect of the leaf extract of $B$. alba justifying its use in traditional system of medicine for the treatment of ulcer. 


\section{Materials and Method}

\section{Plant material}

The fresh leaves of Basella alba L. var. alba Wight, Basellaceae, were purchased from vegetable market of Tripura in the month of Nov 2008. The plant material was identified (Ref. - PARC/2009/258) by Prof. P Jayaraman; Director, PARC, National Institute of Herbal Science, W. Tambaramb (Chennai).

\section{Preparation of extracts}

The fresh leaves of B. alba var. alba were shade dried and powdered. The powdered leaf material was cold extracted separately with ethanol and distilled water. After filtration, the filtrate obtained was concentrated using rotary vacuum evaporator and then dried in lyophilizer (Lobcono, USA) under reduced pressure to get solid mass. The yield of aqueous and ethanol extracts obtained were 8.06 and $6.18 \%$ respectively.

\section{Phytochemical screening}

The AEBA and EEBA were screened for various phytoconstituents such as alkaloids, carbohydrates, glycosides, proteins, sterols and terpenoids as per described methods (Khandelwal \& Kokate, 1995) and the same have been reported earlier as well (Kumar et al., 2011)

\section{Experimental animals}

Albino wistar rats of either sex weighing about 180-210 g were used for the study. The animals were housed in polyethylene cage at $26 \pm 2{ }^{\circ} \mathrm{C}$ and relative humidity of 55-60\%, light and dark cycle of $12 \mathrm{~h}$ each respectively for one week before and during the experiments. Animals were provided with commercial rodent pellet diet (Hindustan Lever) and water ad libitum. All animal in experiments were carried out in accordance with guidelines of CPCSEA (Committee for the purpose of control and supervision on experiments on animals) and the study was approved by the Institutional Animal Ethical Committee as (Ref.-IAEC-48/2008).

\section{Acute oral toxicity studies}

Acute toxicity study was evaluated as per described guidelines (Ecobichon, 1997) in which the rats were fasted overnight and truated with the leaf extracts of B. alba var. alba at doses of 100-2000 mg/ $\mathrm{kg}$ p.o. Increasing doses of extract were administered individually to groups of ten animals and the same were observed daily for seven days. Animals were observed individually at least once during the first $30 \mathrm{~min}$ after dosing, periodically during the first $24 \mathrm{~h}$ and daily thereafter for a period of seven days. All the animals remained alive and there were no significant behavioral and body weight changes during the observations period in which the animals were monitored on regular basis.

\section{Antiulcer studies}

\section{Pylorus ligation model}

Pylorus ligation was performed as described by method (Shay, 1945). Albino rats of either sex were divided into six groups, each group consists of six animals. Group-I represented the control group and was served distilled water (vehicle) orally. Group-II and Group-III served AEBA 200 and $400 \mathrm{mg} / \mathrm{kg}$ each, respectively. Group-IV and Group-V served EEBA 200 and $400 \mathrm{mg} / \mathrm{kg}$ each, respectively. Famotidine, $20 \mathrm{mg} /$ $\mathrm{kg}$, was administered orally for Group-VI as standard drug. All the drugs were administered once daily for five days. The doses were calculated with respect to the body weights of animals and administered orally. On day 6 after the last dose, the rats were kept for $18 \mathrm{~h}$ fasting and care was taken to avoid coprophagy. After $4 \mathrm{~h}$ of pylorus ligation, stomachs were dissected out and cut open along the greater curvature and gastric juice was collected and centrifuged. estimation

Gastric juice, total acidity and free acidity

Four hours after pyloric ligation the rats were sacrificed and the stomach was removed. Gastric juice was collected, centrifuged for $5 \mathrm{~min}$ at $3000 \mathrm{x} \mathrm{g}$, supernatant separated and then analyzed for volume, $\mathrm{pH}$, free acidity and total acidity. Total acid was estimated by titrating against $0.01 \mathrm{~N}$ sodium hydroxide using Topfer's reagent as indicator to find out the free acidity and total acidity expressed as mEq/L (Maity et al, 1986).

\section{Ethanol induced ulcer}

The experiment was performed as per described method (Deshpande et al., 2003). After $24 \mathrm{~h}$ of fasting, the rats were randomly divided into six groups of six animals each. Group-I represented the control group, which received distilled water $+1 \mathrm{~mL} / \mathrm{kg}$ of absolute ethanol orally. Group-II and Group-III received AEBA 200 and $400 \mathrm{mg} / \mathrm{kg}$, respectively. Group-IV and Group-V received EEBA 200 and $400 \mathrm{mg} / \mathrm{kg}$, respectively. Famotidine, at a dose of $20 \mathrm{mg} / \mathrm{kg}$, was administered orally to Group-VI as reference standard drug. After $45 \mathrm{~min}$ of AEBA, EEBA and famotidine treatment, all animals received $1 \mathrm{~mL} / \mathrm{kg}$ of absolute ethanol orally. They were kept in specially 
constructed cages to prevent coprophagia. The animals were anaesthetized $1 \mathrm{~h}$ later of ethanol administration with anesthetic ether and their stomachs removed immediately and fixed in 10\% buffered formalin (Deshpal et al., 2003). Ulcer index was obtained by dividing the total area of the lesions in the stomach by the area of the glandular portion of stomach.

\section{Histopathological evaluation of gastric lesions}

All the groups of animals were fasted over-night prior to being sacrificed. The animals were anesthetized with ether and a midline incision was made in the abdomen to expose out the abdominal organs. The stomach tissue was taken out and preserved in $10 \%$ formalin before microscopic examination. The tissues were then fixed in normal saline for $24 \mathrm{~h}$ and processed through a series of ethyl alcohol of ascending strength $(50,60,70,80$ and 95\%) for period of $1 \mathrm{~h}$, twice in absolute ethanol for $1 \mathrm{~h}$ each and twice in xylene for $1 \mathrm{~h}$ in order to render the tissue elements transparent. The transparent tissues after being cleared of all the elements were embedded in a solid mass of paraplast. The blocks were labelled, allowed to cool and the metal blocks were removed. The solid mass was then trimmed free of excess paraplast, leaving some free margins around the embedded tissues. Five microns thick longitudinal sections were cut with a rotary microtome. The sections were mounted on thoroughly cleaned gelatinized slides and were placed on hot plates at $37{ }^{\circ} \mathrm{C}$ for $24 \mathrm{~h}$ for proper fixation. The slides were then stained by hematoxylin and eosin stain according to the prescribed staining method (Bancroft $\&$ Stevens, 1990). The stain was prepared by dissolving hematoxylin in absolute ethanol. The mixture was boiled rapidly and mercuric oxide was then added. The stain was cooled rapidly in cold water bath; glacial acetic acid was then added and the stain was ready for immediate use. Several stained slides prepared, after drying and labeling were preserved and stored for histopathological studies before microscopic examination for comparative morphological and pathological changes in the control, test drug and standard drug treated gastric tissues of the rat stomach, examined using arbitrary scale (Shah \& Khan, 1973). Grossly (1.8x) with a square-grid eye piece (big square, length $\mathrm{x}$ width $=10 \times 10 \mathrm{~mm}^{2}=$ ulcer area) to assess the formation of ulcer area (hemorrhagic lesions). The length and width of each lesions was determined as (Abdulla et al., 2009) and the sum of the area of all lesion for each stomach was expressed as the ulcer area $(\mathrm{mm} 2)$. Protection ratio of each fraction was calculated using the formula:

$$
\text { Protection ratio }=100-\frac{\text { Ulcer index (test) }}{\text { Ulcer index (control }} \times 100
$$

\section{Statistical analysis}

The data are expressed as mean \pm SEM. Statistical data comparisons were performed using one way ANOVA followed by Dunnet's 't' test. The results were considered statistically significant if $(p<0.05)$.

\section{Results}

\section{Phytocemical screening}

The AEBA showed the presence of amino acids, carbohydrates, flavonoids, proteins, mucilage and saponins whereas EEBA contained amino acids, carbohydrates, favonoids, fixed oil, mucilage, saponins and tannin.

\section{Effect of AEBA and EEBA on pyloric ligation ulcer}

The effect of AEBA and EEBA at dose levels of 200 and $400 \mathrm{mg} / \mathrm{kg}$ and famotidine $(20 \mathrm{mg} / \mathrm{kg})$ as standard drug on the gastric volume, total acidity, free acidity and $\mathrm{pH}$ are shown in Table 1 . Rats pretreated with AEBA and EEBA showed dose dependent decrease in gastric volume $(4.2 \pm 0.12$ and $4.9 \pm 0.16$ $\mathrm{mL}$, respectively), reduced free acidity $(41.6 \pm 0.97$ and $50.4 \pm 0.44 \mathrm{mEq} / \mathrm{L}$, respectively), decreased total acidity $(48.07 \pm 0.88$ and $55.66 \pm 0.33 \mathrm{mEq} / \mathrm{L}$, respectively) and increased $\mathrm{pH}$ value of $6.7 \pm 0.08$ and

Table 1. Effect of plant extract of Basella alba var. alba leaf extract on gastric secretion following pyloric ligation induced ulcer in rats.

\begin{tabular}{lccccc}
\hline \multicolumn{1}{c}{ Treatment } & Dose $(\mathrm{mg} / \mathrm{kg})$ & Vol. of gastric juice $(\mathrm{ml})$ & $\mathrm{pH}$ & Free acidity $(\mathrm{mEq} / \mathrm{I})$ & Total acidity $(\mathrm{mEq} / \mathrm{I})$ \\
\hline Control & -- & $9.3 \pm 0.12$ & $2.6 \pm 0.12$ & $96.2 \pm 1.24$ & $102.3 \pm 1.94$ \\
Famotidine & 20 & $3.3 \pm 0.08^{* *}$ & $7.2 \pm 0.16^{* *}$ & $31.2 \pm 0.16^{* *}$ & $38.2 \pm 0.86^{* *}$ \\
AEBA & 200 & $5.2 \pm 0.11^{*}$ & $5.9 \pm 0.12^{* *}$ & $48.8 \pm 0.18^{*}$ & $57.1 \pm 0.27^{*}$ \\
AEBA & 400 & $4.2 \pm 0.12^{* *}$ & $6.7 \pm 0.08^{* *}$ & $41.6 \pm 0.97^{* *}$ & $48.1 \pm 0.88^{* *}$ \\
EEBA & 200 & $5.9 \pm 0.09^{*}$ & $5.0 \pm 0.12^{*}$ & $52.1 \pm 1.96^{*}$ & $59.5 \pm 0.11^{*}$ \\
EEBA & 400 & $4.7 \pm 0.16^{*}$ & $5.9 \pm 0.10^{* *}$ & $50.4 \pm 0.44^{*}$ & $55.7 \pm 0.33^{*}$ \\
\hline
\end{tabular}

Values are the mean \pm SEM of $\mathrm{n}=6$ rats/treatment. Significance $* p<0.05$, and $* * p<0.01$. 
$5.9 \pm 0.10$, respectively at $400 \mathrm{mg} / \mathrm{kg}$ p.o. as compared to control which showed much higher values with a gastric volume of $9.3 \pm 0.12 \mathrm{~mL}$, free acidity value of $96.2 \pm 1.24 \mathrm{mEq} / \mathrm{L}$, total acidity of $102.3 \pm 1.94 \mathrm{mEq} / \mathrm{L}$ and a $\mathrm{pH}$ value of $2.6 \pm 0.12$. Famotidine showed the most significant activity as compared to control but the effect of EEBA and AEBA were almost similar to it.

\section{Effect of AEBA and EEBA on ethanol induced ulcer}

The antiulcer effect of AEBA, EEBA and famotidine were comparatively studied in ethanol induced gastric ulcer in albino rats. Group I treated with absolute ethanol alone showed gross gastric mucosal lesions in rat's stomach. Group II-V treated with aqueous and ethanol extract at doses 200 and $400 \mathrm{mg} / \mathrm{kg}$ showed dose dependent gastroprotection and simultaneously decreased the ulcer index. The highest gastroprotection and reduction in ulcer index $(1.95 \pm 0.04)$ was obtained in rats treated with $20 \mathrm{mg} / \mathrm{kg}$ of famotidine. AEBA (400 $\mathrm{mg})$ and $\operatorname{EEBA}(400 \mathrm{mg})$ showed an ulcer index value of $2.20 \pm 0.42$ and $3.51 \pm 0.08$, respectively. The control group showed an ulcer index value of $6.9 \pm 0.07$ which was comparatively much higher than animals treated with AEBA, EEBA and famotidine. The percentage protection in ethanol induced ulceration were found to be $71.73,68.11$ and $51.28 \%$ for famotidine, AEBA and EEBA respectively (Table 2).

Table 2. Percentage (\%) protection of plant extracts of Basella alba var. alba leaf extracts in ethanol induced ulcer model.

\begin{tabular}{lccc}
\hline \multicolumn{1}{c}{ Groups } & $\begin{array}{c}\text { Dose } \\
(\mathrm{mg} / \mathrm{kg} / \text { oral })\end{array}$ & Ulcer index & $\%$ Protection \\
\hline Control & $1 \mathrm{~mL}$ & $6.90 \pm 0.07$ & - \\
Famotidine & 20 & $1.95 \pm 0.04 * *$ & $71.73^{* *}$ \\
EEBA & 200 & $4.64 \pm 0.43^{*}$ & 33.19 \\
EEBA & 400 & $3.51 \pm 0.08^{*}$ & $51.28^{*}$ \\
AEBA & 200 & $4.10 \pm 0.09^{*}$ & $40.98^{*}$ \\
AEBA & 400 & $2.20 \pm 0.42 * *$ & $68.11^{* *}$ \\
\hline All values are the mean \pm SEM & $(\mathrm{n}=6$ rats/treatment $)$ & $* p<0.05$ and \\
$* * p<0.01$. & & &
\end{tabular}

Histopathological examination of ulcerated stomach of experimental rats

The cytoprotective effect was confirmed by histological examination. In the rats treated with absolute ethanol, there was markedly extensive damage to the gastric mucosa due to severe disruption of the surface epithelium, deep penetration of necrotic lesions into mucosa and edema of the submucosa layer with leukocyte infiltration of ulcerative tissues (Figure 1). However, rats treated with famotidine, AEBA and EEBA showed gastric mucosal protection as compared to control. Rats treated with EEBA 200 or $400 \mathrm{mg} / \mathrm{kg}$ showed a marked reduction in ulcer areas, milder disruption of the surface epithelium and inhibition of edema and leucocyte infiltration of the submucosal layer. The rats treated with AEBA 200 or $400 \mathrm{mg} / \mathrm{kg}$ showed a mild disruption of the surface epithelium and edema of the submucosa layer with leukocyte infiltration which is comparatively similar to the effects of famotidine $(20 \mathrm{mg} / \mathrm{kg})$. Grossly, the leaf extracts of Basella alba has shown a substantial and significant protection against gastric ulcers in rats.

\section{Discussion}

In order to probe the traditional claim of Basella alba leaf extracts in gastric ulcer, we studied the effectiveness of AEBA and EEBA in preventing gastric ulcer and also assess their antisecretory activity. They were tested against ethanol induced and pylorus ligation induced ulcer in rats. Pylorus ligation induced ulcers are results of auto digestion of the gastric mucosal barrier probably due to excess production and accumulation of $\mathrm{HCl}$ in the stomach (Sairam et al., 2003). Gastric acid is an important factor for the genesis of ulceration in pylorus ligated rats (Shay et al, 1945). The activation of the vagus-vagal reflux by stimulation of pressure receptors in the antral gastric mucosa in the hyper secretion model of pylorus ligature is believed to increase gastric acid secretion (Baggio et al., 2003). The current data clearly demonstrated that, AEBA is comparatively better than EEBA and showed a dose-dependent decrease in hydrogen ion concentration suggesting that the pharmacological mechanism has a relationship to antisecretory and cytoprotective activity (Table.1) in experimental models of gastric lesion induced by absolute ethanol. Ethanol causes severe gastric mucosal ulceration either by direct corrosive effect on the gastric mucosal epithelium or by the release of vasoactive products from mast cells (Szabo, 1987) or release of histamine (Oates $\&$ Hakkinen, 1988). The vascular changes in ethanolinduced gastric mucosal injury and severity of the damage in such injury are associated with extensive lesions of mucosal capillaries, increased vascular permeability and reduction of blood flow in mucosa (Gaskil et al., 1982). Ethanol also produces massive intracellular accumulation of calcium, which represents a major step in the pathogenesis of gastric mucosal injury. This leads to cell death and exfoliation in the surface epithelium. Flavonoids (like quercetin, catechin) seems to play a very important role in the prevention and treatment of peptic ulcer (Middleton et al., 2000). It acts by promoting mucus secretion, thereby serves as gastro protective agent. In addition to this, quercetin has been shown to inhibit the growth of $H$. pylori bacterium in-vitro studies. Catechin interferes with the formation of histamine in gastric mucosa and hence produces the protective effect 


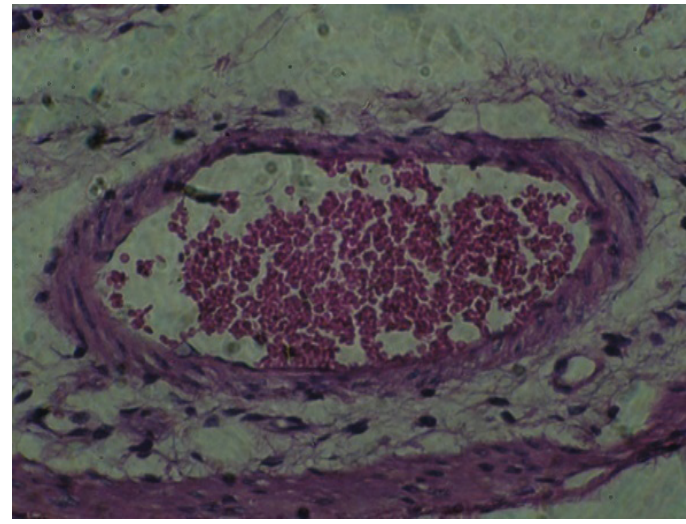

A

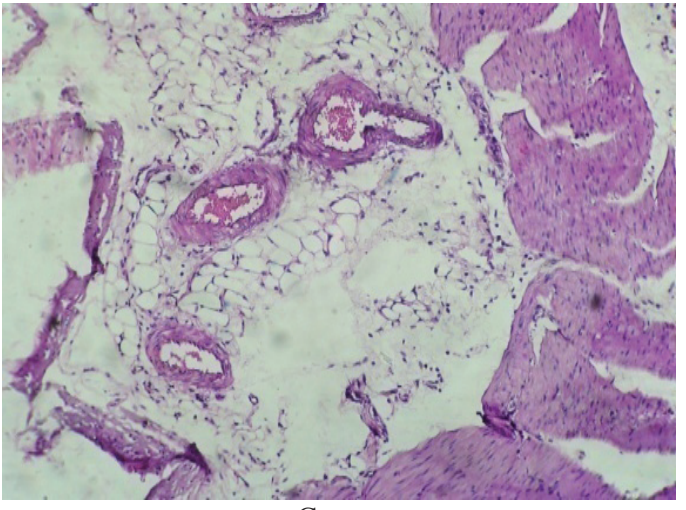

$\mathrm{C}$

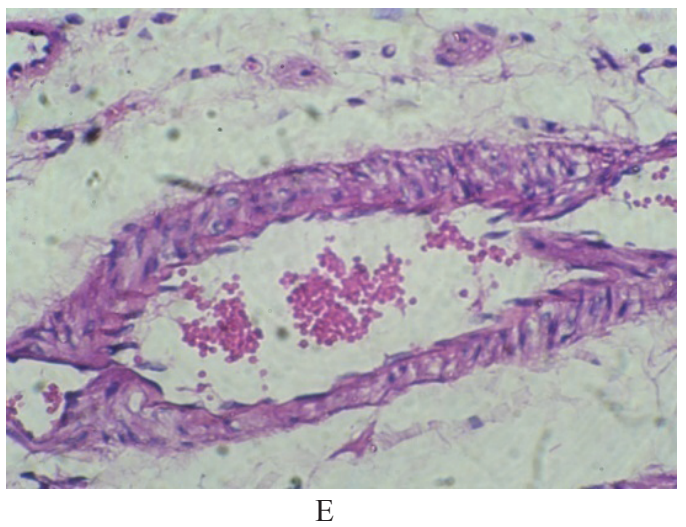

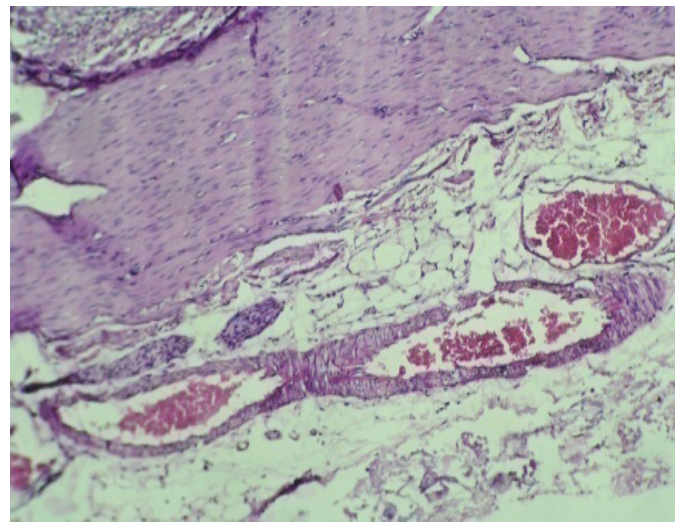

$\mathrm{B}$

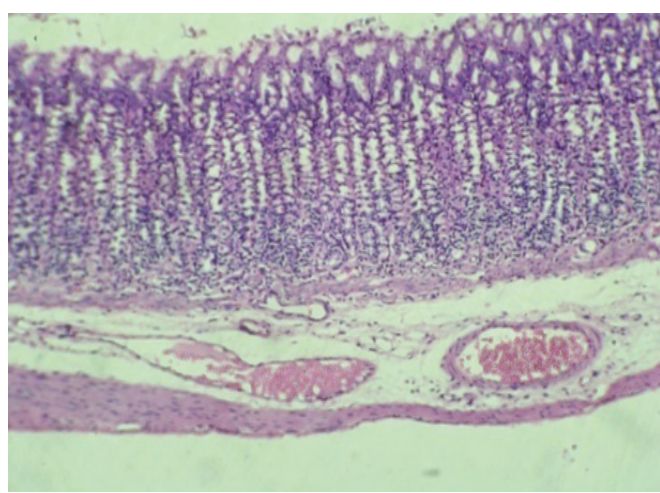

$\mathrm{D}$

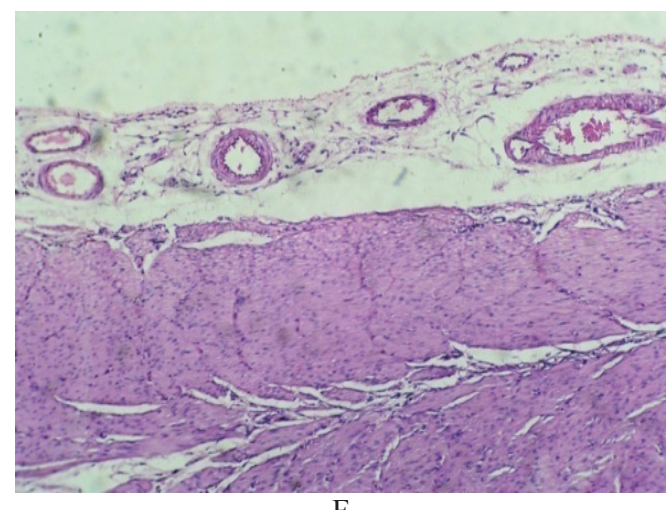

$\mathrm{F}$

Figure 1. Histological evaluation of gastric lesions of ulcerated rats stomach. A. Control (distilled water), (H\&E stain, 10×); B. AEBA $(200 \mathrm{mg} / \mathrm{kg}),(H \& E$ stain, 10×); C. AEBA (400 mg/kg), (H\&E stain, 10×); D. EEBA (200 mg/kg), (H\&E stain, 10×); E. EEBA $(400 \mathrm{mg} / \mathrm{kg}),(\mathrm{H} \& \mathrm{E}$ stain, $10 \times)$; Standard $(20 \mathrm{mg} / \mathrm{kg}),(\mathrm{H} \& \mathrm{E}$ stain, $10 \times)$.

(Middleton et al., 2000). Preliminary phytochemical tests on the aqueous as well as alcoholic extracts of Basella alba have shown the presence flavonoids as well as tannins and this could be responsible for its anti-ulcer activity. The presence of mucilage in the plant could also play a role in cytoprotection. The exact mechanisms underlying the protective action of the leaf extract against ethanol induced gastric lesions are unclear. Further studies are in progress in this lab to explore the compounds responsible for the protective effect and the mechanism of this activity.

\section{Conclusion}

The present study reveal that the leaf extracts of Basella alba var. alba possesses statistically significant antiulcerogenic activity. The activity may be due to enhancement of defensive mechanism through an improvement in gastric cytoprotection or inhibition of acid secretion or both. 


\section{References}

Abdulla MA, Ali HM, Ahmed KA, Noor SM 2009. Evaluation of the anti-ulcer activities of Morus alba extract in experimentally induced gastric ulcer in rats. Biomed Res 20: 35-39.

Baggio CH, Freitas CS, Rieck L, Marques MCA 2003. Gastroprotective effects of a crude extract of Baccharis illinita DC in rats. Pharmacol Res 47: 93-98.

Bancroft JD, Stevens A 1990. Theory and practice of histological techniques. Churchill Livingstone Newyork, 3rd ed, p. 281-282.

Deshpal S, Shah GB, Deshpande I, Parmar NS 2003. Antiulcer activity of aqueous extract of Basella rubra in albino rats. J Nat Remedies 3: 212-214.

Deshpande SS, Shah GB, Parmar NS 2003. Antiulcer activity of Tephrosia purpurea in rats. Indian J Pharmacol 35: 168-172.

Ecobichon DJ 1997. The basis of toxicity testing. CRC Press, New York, 2nd ed. p. 43-49.

Gaskil DL, Serinek KL, Levine VA 1982. Effect of prostacyclin on mucosal blood flow. Surgery 92: 220-224.

Khandare RA, Gulecha VS, Mahajan MS, Mundada AS, Gangurde HH 2009. Evaluation of antiulcer activity of polyherbal formulation. Int J Pharm Res Develop 1: $1-6$.

Khandelwal KR, Kokate CK 1995. Reaction of Cell Content, Practical Pharmacognosy. Nirali prakashan, N. Delhi, v. 2, p. 9-30.

Kumar V, Bhat ZA, Kumar D, Bohra P, Sheela S 2011. In-vitro antiinflammatory activity of leaf extracts of Basella alba var. alba L., Int J Drug Dev Res 3: 176-179.

Maity S, Vedasiromoni J R, Ganguly D K 1986. Antiulcer effect of hot water extract of black tea (Camellia sinensis). $J$ Ethnopharmacol 46: 167-174.

Middleton E, Kandaswami C, Theoharides TC 2000. The effects of plant flavonoids on mammalian cells: implications for inflammation, heart disease, and cancer. Pharmacol Rev 52: 673-751.

Nandkarni KM 1976. Indian Materia Medica. Popular Prakashan Private Limited Publication, Mumbai: $3^{\text {rd }}$ ed. p: $177-178$.

Oates PJ, Hakkinen JP 1988. Studies on the mechanism of ethanol-induced gastric damage in rats, Gastroenterology 94: 10-21.

Pareek V, Singh M, Bhat ZA, Singh P, Kumar D, Sheela S 2010. Studies on mucilage of Basella alba Linn. J Pharm Res 3: 1892-1894.

Sairam K, Priyambda S, Aryya NC, Goel RK 2003. Gastroduodenal ulcer protective activity of Asparagus racemosus; an experimental, biochemical and histological study. J Ethnopharmacol 86: 1-10.

Shah AH, Khan ZA 1973. Gastro protective effect of pretreatment with Zizyphus sativa fruits against toxic damage in rats. Fitoterapia 3: 226-234.

Shay H, Komarov SA, Feels SE, Meraze D, Grunenstein M, Siplet H 1945. A simple method of the uniform production of gastric ulceration in rat. Gastroenterology 5: 43-61.

Szabo S 1987. Mechanisms of mucosal injury in the stomach and duodenum: time-sequence analysis of morphologic, functional, biochemical and histochemical studies. Scan J Gastroent 22: 21-28.

Vyawahare NS, Deshmukh VV, Gadkari MR, Kagathara VG 2009. Plants with antiulcer activity. Phoog Rev 3: 118125.

\section{*Correspondence}

Vijender Kumar

Department of Pharmaceutical Sciences, University of Kashmir, Srinagar (J \& K)-190006

zabhat2000@kashmiruniversity.com

Tel.: 09419077701 